\title{
Instrumentalización de la imagen de la hoja de coca en las tensiones entre el Gobierno local y el Gobierno nacional en la ciudad de Pichari $^{+}$
}

\author{
SOFÍA VIZCARRA* \\ Pontificia Universidad Católica del Perú \\ sofia.vizcarra@pucp.edu.pe \\ https://doi.org/10.18800/rcpg.201701.006
}

\begin{abstract}
Resumen
La escenificación en el espacio y festividades públicas de la hoja de coca en la ciudad de Pichari permite aproximarse al estudio de un espacio de tensión entre el Gobierno local y el Gobierno central en el corazón de una de las principales cuencas cocaleras del Perú, el Valle de los Ríos Apurímac, Ene y Mantaro (VRAEM). A partir del uso de la etnografía enfocada se argumenta que la escenificación de la coca no es solo una disputa por la definición de una marca ciudad, sino una disputa por la legitimidad de la política de drogas. La movilización de los significados tradicionales y políticos de la hoja de coca en el espacio público sirven como recursos de poder simbólico para el Gobierno local en su oposición a las políticas de erradicación. Se exploran tres aspectos de esta disputa: i) los significados movilizados en torno a la hoja de coca, ii) las representaciones en la ciudad y iii) la negociación de la situación en la vida cotidiana. Si bien este no es el único espacio de tensión ente los dos niveles de gobierno, es uno de los pocos que se ha institucionalizado por más de una década.
\end{abstract}

Palabras clave: hoja de coca, poder simbólico, marca ciudad, gobierno local, VRAEM.

Instrumentalization of the image of the coca leaf in the tensions between the local government and the national government in the city of Pichari

\section{Abstract}

The staging of coca leaf in public space and festivals in the city of Pichari allows us to approach the study of tensions between the local government and the central government in the heart of one of the main coca basins of Peru, the Valley of the Apurímac, Ene and Mantaro Rivers (VRAEM). Using focused ethnography, I argue that the staging of coca is not only a dispute for the definition of a city brand but also a dispute over the legitimacy of national drug policy.

\footnotetext{
* Magíster en Ciencia Política y estudiante del Doctorado en Sociología por la Pontificia Universidad Católica del Perú (PUCP).

+ Recibido el 4 de julio de 2017; aceptado el 31 de julio de 2017.
} 
The mobilization of traditional and political meanings of coca leaf in the public space are resources of symbolic power for the local government in its opposition to eradication policies. I explore three aspects of this dispute: i) the meanings mobilized linked to the coca leaf; ii) it representations in the city and iii) the negotiations in daily life. Although this is not the only space of tension between the two levels of government, it is one of the few that has been institutionalized for more than a decade.

Key words: coca leaf, symbolic power, city Brand, local government, VRAEM. 


\section{INTRODUCCIÓN}

Los procesos de descentralización que tienen lugar en América Latina en las últimas décadas han mostrado las potencialidades y las limitaciones de lo que alguna vez fue la esperanza para el fortalecimiento de la democracia en la región. En la década de 1990 se planteaba que la descentralización mejoraría la eficacia de la administración pública, permitiría disminuir la corrupción y el autoritarismo estatal, y acercaría al Gobierno a sus administrados (Nickson, 1995; Ziccardi, 1991). Sin embargo, lo que la literatura sobre los Gobiernos locales evidencia es que estos se convierten en espacios de tensión y mediación entre el nivel local, nacional y global donde se gestionan los cambios políticos, sociales y económicos que ocurren en estos tres niveles. Como lo señala Mack: «las comunidades locales no solo se encuentran en medio de un constante flujo de símbolos y elementos culturales, sino además en un proceso mediante el cual se refuncionaliza también el significado y la importancia de lo local frente a lo nacional» (2002, p. 252).

El protagonismo de lo local frente a lo nacional ha generado tensiones en relación a identidades culturales, modelos económicos y de desarrollo, proyectos políticos, etcétera (Mack, 2002). La cercanía con lo local también ha generado en algunos escenarios latinoamericanos cercanías de los Gobiernos locales con proyectos ilegales, como lo han mostrado diversas investigaciones sobre la conexión entre actividades ilegales y política (Briscoe, Perdomo y Uribe-Burcher, 2014; Garay y Salcedo-Albarán, 2013). En general, estas investigaciones han mostrado que estos nexos se establecen por mecanismos ilegales, como la financiación ilegal de campañas y la corrupción, explorando los beneficios que ambas partes obtienen de manera ilegal. Sin embargo, esta investigación plantea aproximarse a los mecanismos de apoyo legales que pueden servir para beneficiar proyectos ilegales. ¿Es posible desde los Gobiernos locales apoyar directa o indirectamente proyectos ilegales a través de gestiones públicas legales? ¿Acaso esta conexión entre ilegalidad y política siempre debe suceder en la sombra?

A fin de profundizar en el análisis de este tipo de conexión, elegimos el caso de Pichari, el corazón de una de las principales cuencas cocaleras del Perú, el valle de los ríos Apurímac, Ene y Mantaro (VRAEM). Esta cuenca produce el $69 \%$ de la producción potencial de hoja de coca a nivel nacional (UNODC, 2016) y configura uno de los centros de operación del tráfico ilícito de drogas en el Perú. A pesar de que la hoja de coca no fue un cultivo histórico de este municipio, durante los últimos años se ha realizado una escenificación de este 
cultivo en el espacio y festividades públicas. Esta escenificación moviliza la imagen ancestral de la hoja de coca con usos ceremoniales y medicinales. Sin embargo, ello contrasta con un cultivo de hoja de coca con un uso intensivo de agroquímicos (UNODC, 2016; INEI, 2012) que genera daños permanentes al medio ambiente (Bedoya, 2016) y a la salud. Así, parece ser que esta escenificación de la coca constituye un instrumento del Gobierno local para mostrar su apoyo al movimiento cocalero, un actor político importante en la zona. En un contexto en el que el cultivo de hoja de coca y las actividades ilegales conexas representan uno de los principales motores económicos locales, el Gobierno local no puede mantenerse al margen del debate sobre la hoja de coca y su posible erradicación. Así, el espacio público se constituye en un mecanismo más de defensa política de la hoja de coca (Zevallos y Mujica, 2013) desde el Gobierno local. A partir del uso de la etnografía enfocada se argumenta que la escenificación de la coca no es solo una disputa por la definición de una «marca ciudad» (Borja y Castells, 2000), sino una disputa por la legitimidad de la política de drogas que el Gobierno central trata de implementar en el VRAEM. La movilización de los significados tradicionales y políticos de la hoja de coca en el espacio público sirven como recursos de poder simbólico (Hallet, 2003) para el Gobierno local, en su oposición a las políticas de erradicación que se han tratado de implementar sin éxito en la zona. Este análisis sigue con la lectura que tiene Bourdieu sobre poder simbólico, aunque se acota la definición a "la capacidad que tiene un actor de definir la situación en la que se negocia el orden local» (Hallet, 2003, p. 133). Este concepto permite explorar al menos tres aspectos de la disputa entre el Gobierno local y el Gobierno central: i) los símbolos, ii) las representaciones y iii) la negociación de la situación. Si bien este no es el único espacio de tensión entre Gobierno subnacional y Gobierno central en torno a la hoja de $\operatorname{coca}^{1}$, es el único en el que la resistencia local ha tenido éxito y se ha institucionalizado por más de una década.

\footnotetext{
1 Una importante disputa a nivel jurídico entre Gobiernos regionales y Gobierno central ha sido los casos de las ordenanzas regionales que liberaban el cultivo de hoja de coca en Cusco y Huánuco. Dichas ordenanzas fueron declaradas inconstitucionales por el Tribunal Constitucional en el año 2005 (La República, 2005). El Tribunal constitucional reafirmó su posición en el año 2008, declarando inconstitucional la ordenanza del Gobierno Regional de Puno que declaraba patrimonio regional y de interés regional el cultivo de hoja de coca (la sentencia puede ser consultada en la página web del Tribunal Constitucional 2008).
} 


\section{ESCENIFICACIÓN Y PODER SIMBÓLICO}

Las relaciones de poder entre los diferentes actores estatales se expresan de diferentes formas: en el discurso, en los términos de las negociaciones, así como en el uso y las representaciones en el espacio público. Las culturas prehispánicas como los wari y los incas tenían presente que el componente espacial era clave al momento de imponer su dominación legitima sobre las culturas conquistadas (Acuto, 2012; Nash, 2012; Nash y Williams, 2005). Asimismo, autores en diferentes contextos se han aproximado a los usos políticos del espacio, especialmente para legitimar ideologías y prácticas políticas a nivel nacional (Bell, 1999; Daniels, 1993; Johnson, 1995). Para estos autores, tanto el espacio público como las festividades públicas son herramientas para crear una narrativa hegemónica sobre la identidad local (Bell, 1999, p. 184). A partir de la apropiación de estas manifestaciones públicas, permite la «activación simbólica del tiempo y del espacio», las representaciones públicas se convierten en mitos concretizados que proyectan una identidad en el espacio público (Daniels, 1993).

Las narrativas hegemónicas proyectadas en el espacio público forman parte del orden social de la ciudad. Si consideramos que el orden social no es fijo sino que se negocia constantemente en las interacciones cotidianas de los actores (Strauss, 1978; Hallet, 2003), entonces la legitimidad de estas narrativas depende de su grado de aceptación por parte de los actores que no las produjeron. La literatura se ha centrado principalmente en el rechazo de ciertos usos del espacio desde la sociedad civil. Sin embargo, desde el Estado también pueden surgir contestaciones a los usos y narrativas que se proyectan en el espacio. Especialmente si tomamos en consideración que en un contexto de descentralización existen ciertas competencias que son exclusivas de los Gobiernos locales, como el ornato público, el esparcimiento y festividades locales. Ello puede llevar a que los usos del espacio público generen tensiones entre los diferentes niveles de gobierno y sea un escenario de disputa entre dos poderes.

\section{LA ETNOGRAFÍA ENFOCADA Y LAS PRÁCTICAS COTIDIANAS EN RELACIÓN AL ESPACIO Y FESTIVIDADES PÚBLICAS EN LA CIUDAd DE PICHARI}

El recojo de información se realizó a partir de la técnica de etnografía enfocada (Montes de Oca, 2015), la cual adapta el enfoque tradicional de etnografía antropológica a los contextos actuales y los desafíos metodológicos que 
presentan. Estas adaptaciones incluyen el desarrollo de técnicas específicas como la etnografía multisituada (Marcus, 1995) o la ampliación a campos no tradicionales de la etnografía como el Estado (Agudo-Sanchíz y Estrada, 2011, Montes de Oca, 2015). Las principales diferencias entre el paradigma tradicional (Radcliffe-Brown, 1958; Geertz, 1973; Weiss, 1995) y la propuesta de etnografía enfocada se resumen en la tabla 1.

Tabla 1. Etnografía tradicional y enfocada: elementos de contraste

\begin{tabular}{|c|c|c|}
\hline Duración & Etnografía tradicional & Etnografía enfocada \\
\hline $\begin{array}{c}\text { Construcción de la } \\
\text { profundidad }\end{array}$ & $\begin{array}{c}\text { Intensidad temporal de la } \\
\text { información construida }\end{array}$ & $\begin{array}{c}\text { Intensidad de la información } \\
\text { construida }\end{array}$ \\
\hline Soporte & Énfasis en la escritura (notas) & $\begin{array}{c}\text { Combinación de escritura y } \\
\text { grabación (notas y transcripción de } \\
\text { audio y video) }\end{array}$ \\
\hline Alcance & Mirada holística en todos los \\
aspectos del campo & $\begin{array}{c}\text { Mirada enfocada en ciertos aspectos } \\
\text { del campo }\end{array}$ \\
\hline Objeto de estudio & $\begin{array}{c}\text { Sociedades ajenas (estudio de lo } \\
\text { extrańo: strageness) }\end{array}$ & $\begin{array}{c}\text { Sociedad propia (estudio del alter } \\
\text { ego, alterity) }\end{array}$ \\
\hline Lenguaje & Aprender el idioma nativo & $\begin{array}{c}\text { Familiarizarse con el lenguaje } \\
\text { particular (sociolectos: tecnicismos, } \\
\text { argot, no verbal) }\end{array}$ \\
\hline
\end{tabular}

Fuente: Montes de Oca (2015, p. 28).

Los periodos de inmersión fueron varios y duraron entre cinco y diez días, el conocimiento previo del terreno, durante más de cinco años, ayudó a que las breves inmersiones etnográficas permitan el recojo de información importante de descripciones, la cual se encuentra condensada en los cuadernos de campo elaborados para las salidas realizadas en los meses de junio de 2015 y enero y agosto de 2016. La selección de los periodos de campo se hizo en función de las disponibilidades de tiempo y condiciones climáticas, a excepción de la salida de agosto de 2016. Esta última salida se enfocó en etnografía en el Festival Internacional de la Coca que se realiza entre el 3 y el 9 de agosto para conmemorar el aniversario de la ciudad. 
La etnografía urbana permite aproximarse a un espacio a partir de las interacciones que allí se producen. No se trata en estricto de seguir a determinado grupo social, sino de aproximarse a un espacio identificando actores que allí conviven y circulan. La noción de circuitos (Magnani, 2012, p. 97) permite esbozar una clasificación de espacios, no necesariamente contiguos, relacionados a un mismo rubro o prácticas donde circulan e interactúan actores, produciendo identidades y significados particulares. Para ello se observó e interactúo con las personas en conversaciones informales a fin de poder recoger la información necesaria. En todo momento se informó a los participantes que se estaba realizando una etnografía en el marco del desarrollo de una tesis doctoral en la Pontificia Universidad Católica del Perú, respetando lo previsto en el dictamen otorgado por el Comité de Ética de la Universidad. En esta investigación, la noción de circuito se emplea para observar en la ciudad los espacios de escenificación de la coca y las interacciones que se producen dentro de estos espacios entre actores del Gobierno local y central. Se documentó la información referida a los circuitos a partir de notas de campo y fotografías durante el trabajo de campo.

\section{EXPANSIÓN DEL GOBIERNO CENTRAL Y FORTALECIMIENTO DEL Gobierno local en Pichari}

\section{Pichari: el desarrollo de un centro administrativo en el corazón del VRAEM}

El valle de los ríos Apurímac, Ene y Mantaro es la principal cuenca cocalera del Perú, con un total de 18333 hectáreas de coca cultivada (UNODC, 2016). El distrito de Pichari se encuentra en el corazón del VRAEM y funciona como uno de los centros administrativos de la localidad. Desde la creación del Plan VRAEM en 2004, así como sus posteriores formulaciones, se ha reforzado la presencia del Gobierno central en la zona como parte de la estrategia de lucha contra el tráfico ilícito de drogas y pacificación. Estos planes no solo implicaron la presencia de las fuerzas del orden sino la presencia de agencias civiles encargadas de proveer diferentes servicios a la ciudadanía. Ello significó que progresivamente Pichari se convirtió en el lugar de trabajo y residencia de diversos servidores públicos, quienes cotidianamente convivían con los habitantes locales.

Así, en la última década se han instalado diversas instituciones públicas en Pichari: la base militar del Comando Conjunto, el Frente Policial, el Ministerio Público, el Poder Judicial, las sedes de diferentes ministerios y agencias del 
Poder Ejecutivo, entre otros. Además, hasta fines del año 2016 allí funcionó la secretaría de la Comisión para el Desarrollo del VRAEM (Codevraem), hasta que fue absorbida por Devida, la agencia coordinadora de la política de drogas del Perú. Del recorrido por el casco urbano de la ciudad se pudo observar que al menos 26 instituciones del Gobierno central tienen una sede, como se resume en el gráfico 1.

Gráfico 1. Instituciones públicas presentes en el casco urbano de Pichari

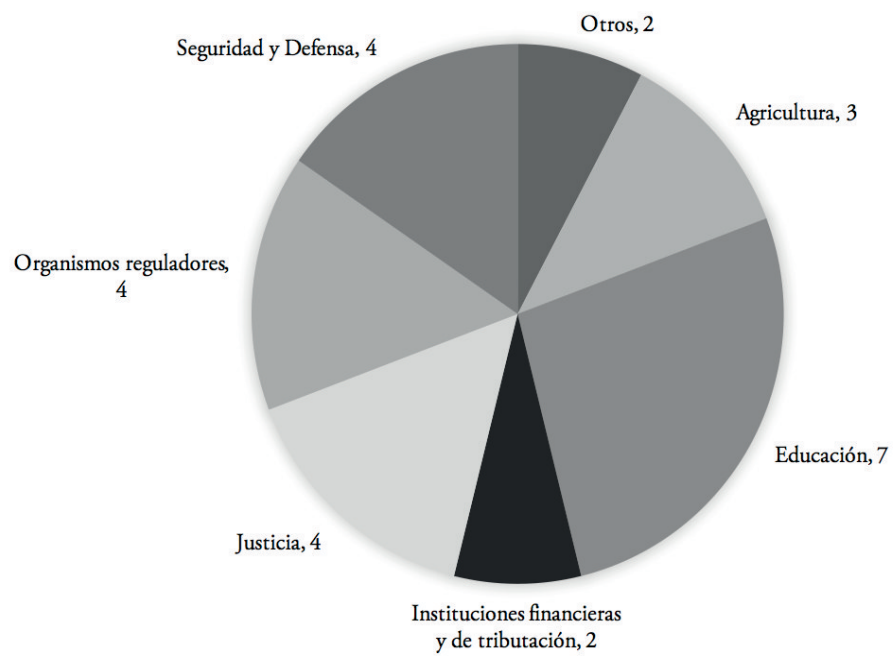

Fuente: Elaboración propia sobre la base de observación en la ciudad de Pichari en febrero de 2016.

La composición de la población de Pichari también ha cambiado en la última década, dando cabida a un mayor número de funcionarios públicos. A pesar de que existe una alta rotación entre ellos, especialmente entre las fuerzas del orden, la presencia de funcionarios del Gobierno central es permanente en la ciudad, lo que ha llevado a que la población local los conozca y se familiarice en su vida cotidiana con los servicios ofrecidos por el Gobierno central. Incluso algunos dueños de comercios con quienes se conversó durante el trabajo de campo señalan que los servidores públicos son su principal clientela.

\section{Gobierno local y capacidad de gasto}

La distritalización de Pichari data del año $1995^{2}$, anteriormente formaba parte del distrito de Echarate en la provincia de La Convención. En ese sentido,

\footnotetext{
2 El distrito fue creado el 9 de agosto de 1995, mediante la ley 26521.
} 
es tardíamente que Pichari comienza a ser una zona de interés administrativo. Gracias a su potencial para su expansión espacial y desarrollo urbano, Pichari se configuró como un centro administrativo del VRAEM, tan e incluso más importante que la ciudad de Ayna-San Francisco. Sin embargo, este no es el único factor que explica su importancia. Los recursos manejados por el Gobierno local son también una importante diferencia con respecto a sus pares ayacuchanos.

Los recursos del canon marcan también el interés que ha generado el distrito. A pesar de su reciente creación, la autoridad municipal gana protagonismo a partir del ańo 2005, cuando el distrito comienza a recibir regalías por la explotación del gas de Camisea. A diferencia de sus pares ayacuchanos, las autoridades de los distritos cusqueños del VRAEM cuentan con importantes recursos que han destinado principalmente a obras de infraestructura. Tan solo entre mayo de 2005 y mayo de 2008 la Municipalidad de Pichari recibió más de 57,7 millones de soles (Chávez, 2008). A partir de ese periodo el crecimiento de los recursos provenientes del canon ha fortalecido la capacidad de gasto del Gobierno local, como se observa en el gráfico 2.

Gráfico 2. Evolución del presupuesto ejecutado y de los recursos provenientes del canon de la Municipalidad de Pichari entre los años 2007 y 2015

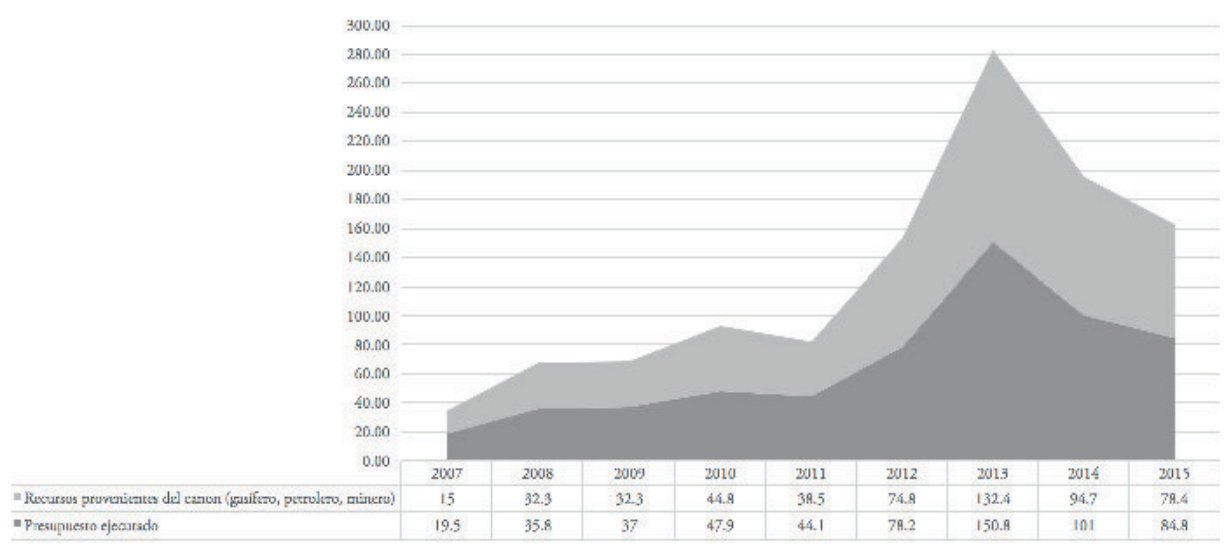

Fuente: Elaboración propia a partir de recursos disponibles de Consulta Amigable-MEF. 
En el acumulado, el canon gasífero ha representado alrededor del 60\% del presupuesto municipal entre los años 2005 y 2015 (MEF, s/f). El gasto de estos recursos se ha destinado principalmente a infraestructura, como la plaza central, el mercado o el campo ferial. Esta capacidad de gasto ha sido usada por el Gobierno local para generar empleo y, como señalan algunas de las personas con las que se sostuvo conversaciones durante el trabajo etnográfico, a pagar favores y generar redes de apoyo político. Este pago de favores incluiría la defensa explicita de la hoja de coca en el espacio público y la creación de una marca ciudad alrededor de ella. No obstante, ello no hubiese sido posible si no existiesen discursos legitimadores de la hoja de coca que el Gobierno local pudiese movilizar en torno a esta escenificación.

\section{IMÁGENES MOVILIZADAS DE LA HOJA DE COCA: LA IMAGEN TRADICIONAL Y LA IMAGEN POLÍTICA}

Los significados asociados a la hoja de coca son diferentes según las formas de su uso, como lo señala Mayer (2004, p. 197), existe una diferencia entre la hoja de coca como mercadería global, asociada a los derivados cocaínicos ilegales, y la coca como mercadería local, asociada a los usos tradicionales de la coca en las sociedades andinas. Este último uso es objeto desde hace varias décadas de una revalorización por diferentes intelectuales latinoamericanos, quienes defienden los usos lícitos de la coca (Instituto Indigenista Americano, 1986; Mayer, 1993). Es en base a este último uso que se ha construido su legitimidad política, oponiéndose a su prohibición. Ello ha servido de base para que los gremios cocaleros construyan una plataforma de defensa de este cultivo en los países andinos, especialmente en Bolivia. Esta sección se enfoca en presentar los significados tradicionales y políticos asociados a este cultivo.

\section{La imagen tradicional de la hoja de coca}

La hoja de coca ha tenido roles importantes en diferentes momentos de nuestra historia. Los investigadores identifican al menos tres periodos importantes de la historia peruana en lo referente a los roles de la hoja de coca: i) la época prehispánica, ii) la época colonial y iii) la época republicana (o moderna). Los roles como los significados que se han asociado a la hoja de coca en cada una de estas épocas han permitido construir una imagen legítima de la hoja de coca, alejada del narcotráfico y asociada a tradiciones históricas del país. Es necesario entender los elementos que le otorgan legitimidad histórica a la hoja de coca para luego comprender cómo su imagen es instrumentalizada en Pichari en la actualidad. 
Como lo señala Lloréns (Rospigliosi, Blondet y Lloréns, 2004), en el periodo prehispánico se han hallado diversas evidencias del uso de la hoja de coca para fines rituales tanto en épocas pre incas como incas. Asimismo, existe un debate en torno al uso cotidiano de la hoja de coca durante esa época. A pesar de que durante mucho tiempo se creyó que su uso era únicamente ritual, los autores señalan que ello obedece más a una mala interpretación sobre la diferencia entre acceder y distribuir hoja de coca (Murra 1986 citado en Mayer, 2004, p. 200). El uso tradicional de la coca en esa época tenía una doble función: como moneda de intercambio (Burchard, 1974, 1978) y como bien de lujo que tiene «tanto un valor gratificante personal como un valor social» (Mayer, 2004, p. 199).

Durante la época colonial surgen nuevos usos de la hoja de coca que la asocian con la esfera laboral, pero también con la explotación de las poblaciones indígenas. La expansión de su cultivo durante esa época obedece al hecho de que era destinada al consumo de los indígenas que trabajaban en las distintas minas del virreinato (Miranda, 2016, pp. 102-103). Así, la coca se incorpora a los rituales religiosos y la vida social de la mina (Bouysse-Casagne, 2005; Orche, 2008). Es durante este periodo que la coca se expande en las haciendas del río Apurímac, especialmente en las zonas que son hoy las provincias ayacuchanas de Huanta y La Mar, siendo uno de los principales productos de la economía colonial de la época. Se difunde así la práctica del chacchado de coca, la cual se internacionaliza, llegando incluso a zonas donde no existía este producto como las salitreras del norte de Chile (Miranda, 2016). Es durante este periodo que se sientan las bases para la existencia de un consumo tradicional de coca importante en el país.

Durante el periodo republicano, el consumo tradicional así como laboral continúa a la par de los usos rituales. Como lo señala Lloréns, «durante la época republicana, la asociación entre la condición indígena y el consumo de hojas de coca se encuentra presente en prácticamente todos los autores que se dedican a cualquiera de estos dos temas» (Rospigliosi, Blondet y Lloréns, 2004, p. 128).

\section{Usos contemporáneos de la hoja de coca en el Perú}

En el Perú se han realizado dos censos sobre el consumo tradicional de hoja de coca, uno en el año 2003 publicado en 2004 y otro en el año 2013 publicado en 2015 (INEI-Devida, 2015; Rospigliosi, Blondet y Lloréns, 2004). La idea de estos censos fue la de identificar las brechas entre la demanda legal (ya sea industrial o tradicional) de hoja de coca y la oferta real del mercado (estimada a partir de las cifras de Naciones Unidas y del Censo Nacional Agropecuario (Cenagro). La pregunta tras estos esfuerzos era permitir identificar el excedente 
de hoja de coca que se destina al mercado ilegal y finalmente a la elaboración de derivados cocaínicos.

Los principales datos del censo (INEI-Devida, 2015) muestran que existían en 2013 más de 3,4 millones de consumidores de hoja de coca con diversos usos legales, quienes consumían 10,728 toneladas de hoja, lo que representa un aumento de $22,1 \%$ de la cantidad de hoja de coca demandada en 2013. Los principales usos que se le da a dicha hoja son el chacchado $(43,1 \%)$, invitar a peones y jornaleros $(31,6 \%)$ y curación de síntomas y malestares $(27,8 \%)$, el detalle de dichos usos se observa en la tabla 2 :

Tabla 2. Perú: Demanda de la hoja de coca, según formas de adquisición

\begin{tabular}{|l|c|c|}
\hline \multicolumn{1}{|c|}{ Forma de adquisición } & $\begin{array}{c}\text { Número de } \\
\text { personas }\end{array}$ & Porcentaje (\%) \\
\hline Compró u obtuvo hoja de coca & 3464681 & 100,0 \\
\hline Compró hoja de coca & 3370736 & 97,3 \\
\hline $\begin{array}{l}\text { Para chacchar (en el trabajo agrícola, comunal, en } \\
\text { construcción, artesanal, en el hogar, etc.) }\end{array}$ & 1483073 & 43,1 \\
\hline Para invitar a peones y jornaleros & 1093263 & 31,6 \\
\hline Curación de síntomas y malestares & 962488 & 27,8 \\
\hline Velorios, misas, entierro, día de los muertos, etc. & 716196 & 20,7 \\
\hline Para el marcado de animales, pago a la tierra, apus, etc. & 473811 & 13,7 \\
\hline Fiestas costumbristas, patronales y carnavales & 424078 & 12,2 \\
\hline Adivinación, atraer suerte & 233761 & 6,7 \\
\hline Otros usos & 398917 & 11,5 \\
\hline Obtuvo hoja de coca & 147927 & 4,3 \\
\hline De su chacra & 33676 & 2,4 \\
\hline De su negocio & 33899 \\
\hline Mediante trueque & 3255 \\
\hline
\end{tabular}

Nota: Pregunta con respuesta múltiple.

Fuente: INEI-Devida (2015, p. 30). 
Tanto la encuesta de 2003 como la de 2013 muestran que el consumo tradicional de hoja de coca persiste hasta el siglo XXI y forma parte de las tradiciones locales. Así, en el Perú subsisten los dos usos de la coca identificados por Mayer. Por una parte, su uso tradicional que emplea el 11\% de la producción potencial de hoja de coca en el Perú al año 2015 (96 304 TM). Por otra parte, su uso global, conectado a la cadena de suministro global de drogas cocaínicas ilegales, que emplea $89 \%$ de la producción anual de hoja de coca seca. A ello hay que sumarle el uso figurativo de la hoja de coca como símbolo político que se ha construido desde inicios de los ańos 2000.

\section{Simbolismo político de la coca a nivel internacional}

Además de la imagen tradicional del consumo de coca ligado a su valor histórico y social, la hoja de coca ha servido como símbolo de movilizaciones políticas, cuyo ejemplo más claro es el MAS en Bolivia. La construcción de la imagen política parte del reconocimiento del rol histórico y social que tiene la hoja de coca en Bolivia. En ese sentido, autores mencionan que «Si la coca [...] desapareciese en forma gradual o brusca, las consecuencias podrían conducir a una quiebra de la cohesión social y la salud psíquica de proporciones nunca vistas en el país» (Carter y Mamani, 1986, p. 292, citado en Mattos, 2014, p. 34).

En Bolivia, el despliegue de programas de erradicación de cultivos financiados por la cooperación estadounidense sirve como detonador para organizar una plataforma de defensa política de la coca que se transformaría posteriormente en uno de los movimientos políticos más importantes del país. Los analistas del caso boliviano califican al «enfrentamiento entre productores de coca del Chapare y el gobierno, a través de fuerzas especiales militares y policiales encargadas de la erradicación de cocales, es sin duda alguna el más violento y prolongado en la era neoliberal» (Mattos, 2014, p. 32). Se configura entonces no solo un conflicto en torno a la actividad puntual del cultivo de coca, sino que dicho conflicto se vuelve la escena para una tensión ideológica y política internacional. La coca se vuelve un símbolo de resistencia para la imposición internacional de políticas locales y, por lo tanto, gracias a la confluencia de al menos tres factores: «lo cultural, el imaginario de resistencia y lo político inesperado", se configura como una causa política nacional y no meramente en un conflicto local (Mattos, 2014, p. 37). Con la llegada de Evo Morales al poder y el retiro del Estado boliviano de la Convención Única de 1961 y de su posterior re adhesión en 2013, se vuelve a poner en la discusión internacional 
el rol de la hoja de coca y los problemas asociados a su criminalización. Esto renueva la legitimidad internacional del cultivo, especialmente en el marco del movimiento de reforma de la política de drogas.

Así, los actores locales cuentan con dos fuentes de legitimidad para utilizar la imagen de la hoja de coca en sus reivindicaciones políticas, y en general en la construcción de una «marca ciudad» (Borja y Castells, 2000) en torno a la imagen de la coca. Por una parte, una legitimidad interna asociada al uso tradicional de la coca y su importancia en la vida social andina, que llegó al VRAEM con los migrantes altoandinos provenientes de Ayacucho, Cusco, Huancavelica y Junín. Por otro lado, la cercanía con Bolivia y la fortaleza (al menos durante la primera década del siglo XX) del movimiento cocalero también les ha permitido retomar la legitimidad externa de la hoja de coca como símbolo de resistencia política. Son estos significados en torno a la hoja de coca los que se ponen en escena en la ciudad y en sus festividades.

\section{EsCENIFICACIÓN DE LA HOJA DE COCA EN LA CIUDAD}

En la ciudad de Pichari no hay coca, al menos no en forma de planta, sin embargo la imagen de la coca es omnipresente en la ciudad. Son dos espacios físicos y simbólicos los que permiten escenificar a la hoja de coca como parte de la imagen de la ciudad. Esta construcción de «marca ciudad» cocalera ha sido iniciativa del Gobierno local, el cual ha empleado los recursos recibidos por el canon para realizar las remodelaciones de algunos espacios públicos y comenzar a organizar el Festival Internacional de la Coca para conmemorar el aniversario de fundación del distrito de Pichari. Ambos espacios son el escenario en el que las autoridades locales utilizan la imagen de la coca como un elemento de poder simbólico para establecer el contexto en el que se desarrolla la negociación del orden social con los representantes del Gobierno central en torno a la política de drogas.

\section{Escenificación de la coca en el espacio público}

El principal espacio público de escenificación de la hoja de coca es la plaza central, donde se encuentra el paseo de las hojas de coca. Cada uno de los lados del paseo simboliza el día (9 hojas) y el mes (8 hojas) del aniversario de Pichari. Se trata de hojas de más de dos metros de alto con inscripciones sobre el carácter ancestral y sagrado de la hoja, como se observa en la fotografía 1, que conforman el ornato central de la plaza. 


\section{Fotografía 1. Paseo de la coca en la plaza de Pichari}

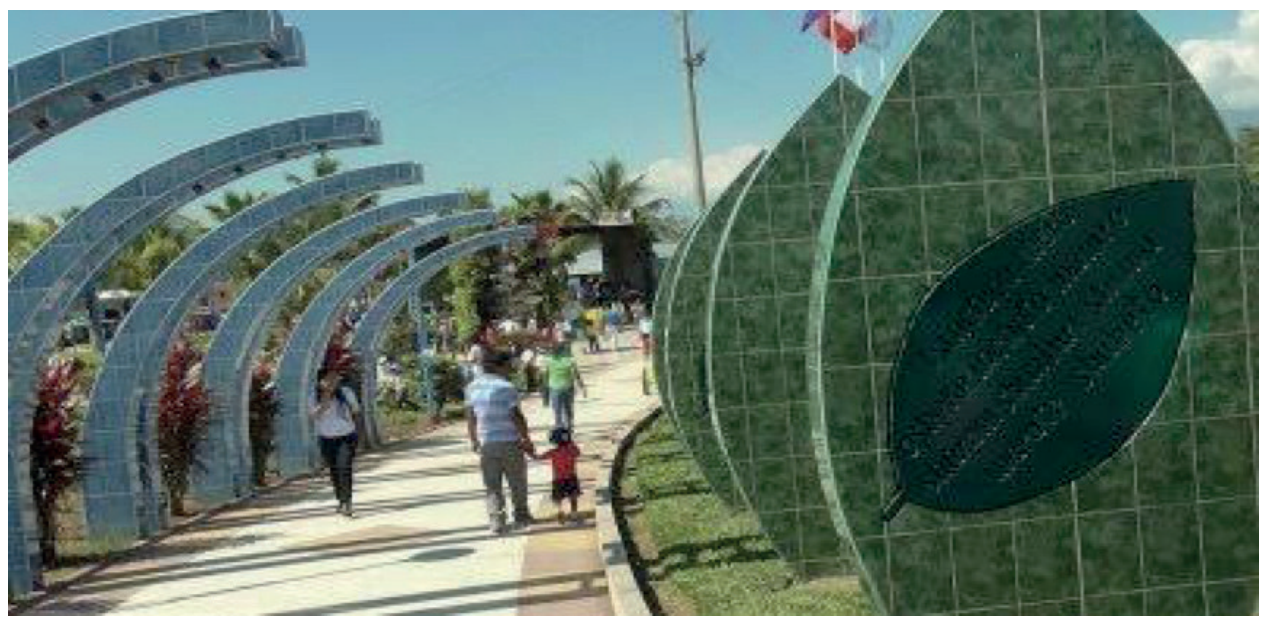

Fuente: Municipalidad de Pichari.

Este paseo de la hoja de coca es uno de los primeros monumentos públicos construidos por la municipalidad cuando empezaron a llegar los recursos del canon. La primera versión de la construcción de este paseo se realiza en 2005, durante la primera gestión de Joaquín Dipas como alcalde de Pichari (20032006), la tabla 3 presenta las principales características del perfil SNIP original. Los entrevistados locales señalan que Dipas logra llegar a la alcaldía con el apoyo del movimiento cocalero, por lo tanto en muestra de agradecimiento decide adoptar distintas iniciativas a favor de la revalorización de la hoja de coca en el distrito.

Este primer proyecto de construcción (el único del cual se ha encontrado un expediente técnico) contempló la construcción de la plaza y el paseo de la coca en lo que antes era un terreno baldío, pero que estuvo reservado para la construcción de la plaza desde la planificación de la ciudad en la década de 1960. El perfil del proyecto de inversión pública no menciona explícitamente la construcción del paseo de la coca, sin embargo en la sección de viabilidad sociocultural del proyecto se menciona que:

De acuerdo a las consultas referentes a la ejecución del proyecto de inversión, la población de la zona se encuentra en total acuerdo, no se oponen a la realización del mismo, esto se demuestra con la priorización del proyecto en el presupuesto participativo, como consta en acta. La ejecución del proyecto es prioritario desde el punto de vista social, es viable ya que incrementara el desarrollo social económico del distrito de Pichari (MEF, 2005). 
Tabla 3. Principales características del proyecto SNIP de construcción de la Plaza de Armas de Pichari

\begin{tabular}{|c|c|}
\hline Rubro & Datos contenidos por el perfil SNIP \\
\hline Código de proyecto SNIP & 23858 \\
\hline Responsable funcional & Vivienda, Construcción y Saneamiento \\
\hline Unidad formuladora & $\begin{array}{c}\text { Sub-gerencia de inversiones y desarrollo urbano, } \\
\text { Municipalidad Distrital de Pichari }\end{array}$ \\
\hline Unidad Ejecutora & Municipalidad distrital de Pichari \\
\hline Responsable de la Unidad Ejecutora & Ing. Miky Joaquín Dipas Huamán \\
\hline Fecha de formulación del proyecto & $15 / 07 / 2005$ \\
\hline Fecha de aprobación del proyecto & $28 / 09 / 2005$ \\
\hline Costo de la elaboración del perfil & S/. 2,000 \\
\hline Número de beneficiarios & 5064 habitantes \\
\hline Contenidos de alternativa ganadora & $\begin{array}{l}\text { Construcción de la Plaza Principal de Pichari } \\
\text { Programa de capacitación y sensibilización en la } \\
\text { conservación de ornato público y medio ambiente }\end{array}$ \\
\hline Costo total del proyecto (a costo de mercados) & S/. 91958200 \\
\hline
\end{tabular}

Fuente: Elaboración propia a partir de información del Sistema SNIP del MEF (MEF, 2005).

Dos puntos son resaltantes con respecto a esta escueta explicación presentada en el perfil técnico. En primer lugar, el aparente consenso sobre la necesidad de la construcción de la plaza. Aunque no se menciona nada sobre la descripción del ornato público ni si ello fue explicitado en la sesión del presupuesto participativo. El otro punto es el vínculo con el incremento del desarrollo social y económico del distrito. Se entiende, por lo tanto, que de alguna manera, no explicitada en el documento, este espacio público va a contribuir con el desarrollo económico de la ciudad. Lo cierto es que luego de la inauguración de la plaza a fines del año 2005, las propiedades ubicadas en dicho espacio se revalorizaron. Asimismo, se convirtió en el espacio de convivencia física entre el Gobierno local (el local de la municipalidad distrital) y el Gobierno central (con la presencia del Plan VRAEM, Indecopi, OEFA, Midis, entre otras agencias gubernamentales). 
Lo que se logra desde el Gobierno local es imponerle a los funcionarios del Gobierno central una convivencia cotidiana con la presencia de la hoja de coca, varios de los funcionarios con quienes se dialogó señalan que es imposible olvidar que uno está en el VRAEM cuando uno abre la ventana de su oficina y ve una hoja de coca de dos metros al frente. En ese sentido, el Gobierno local usa el poder simbólico para asumir una abierta defensa de la hoja de coca y marcar su oposición a la política de drogas. Queda claro, desde la llegada a la ciudad, que la hoja de coca es un símbolo central de este espacio. Esta idea se complementa con obras de ornato público que han realizado administraciones locales en años posteriores.

Así, desde la «i» del nombre del distrito que aparece en la plaza, hasta las ventanas de los baños públicos, tienen forma de hoja de coca. Asimismo, el símbolo de la ciudad es Coca Kinto, un muńeco conformado por varias hojas de coca y vestido con una túnica de los colores del Tawantinsuyo, como se aprecia en la fotografía 2.

Además de estar en todos los afiches y material comunicacional de la plaza de Pichari, Coca Kinto fue incluido como ornato público de la plaza de Pichari en una esquina que podríamos denominar «la esquina de la coca». En dicha esquina se encuentran dos esculturas con referencia a la hoja de coca. Una es la escultura de pago a la tierra con hojas de coca, que se aprecia en la fotografía 3, y la otra es la escultura de Coca Kinto.

La imagen de la coca es parte de la vida cotidiana de Pichari. El discurso local se liga al carácter ancestral, milenario y curativo de la coca, se la trata como herencia histórica, a pesar de que no corresponde a la historia local marcada por la presencia de pueblos indígenas asháninkas y matsiguengas que no cultivaban dicha planta, como se ha podido recoger de los testimonios de antiguos pobladores de Pichari.

Los habitantes locales están conscientes que existe una relación entre coca y narcotráfico, aunque prefieren no señalarla directamente. No ofrecen una resistencia a hablar del tema pero tampoco tienen una actitud de rechazo frontal a esta conexión. A partir de lo que se recogió durante el trabajo de campo, el principal discurso entre los habitantes de Pichari se construye en torno a la idea de que en la zona se cultiva la coca pero se desconoce el uso que le dan a la misma. Es una suerte de «desatención cortés» (Goffman, 1967) que permite a los diversos actores continuar con su vida cotidiana en la ciudad. Los habitantes locales no asumen una defensa explícita de la coca pero tampoco critican la presencia de su escenificación en la ciudad. Ninguno le reclama al municipio sobre el uso de los recursos en este tipo de obras ni cuestiona en voz alta que la hoja de coca sea parte de la ciudad. La desatención cortés fortalece por lo tanto el poder simbólico que se moviliza con la escenificación de la coca. 
Fotografía 2. Coca Kinto, símbolo de la ciudad de Pichari en la plaza de la ciudad

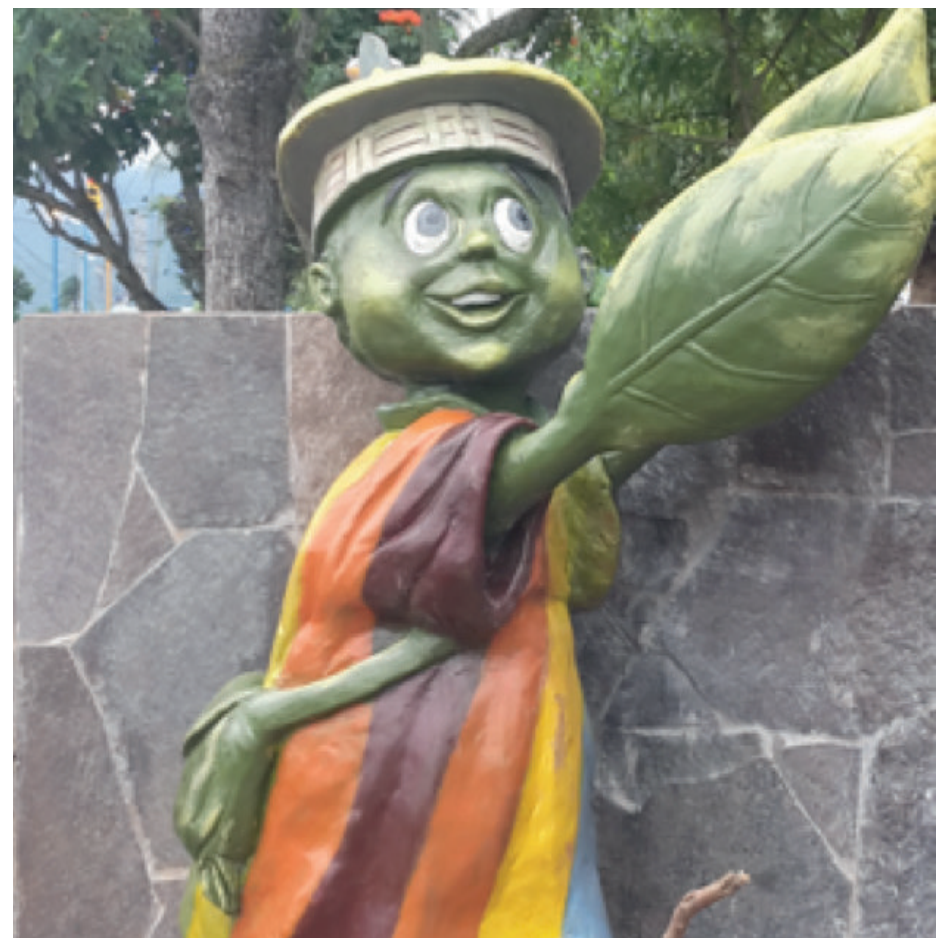

Fuente: Archivo fotográfico propio.

Fotografía 3. Monumento al pago a la Pachamama con hojas de coca

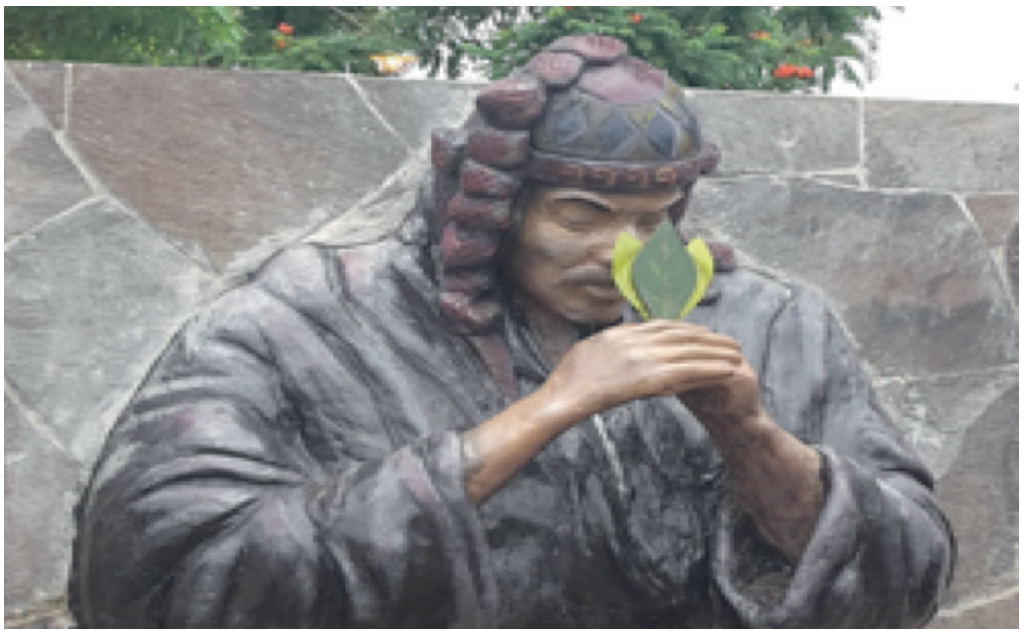

Fuente: Municipalidad de Pichari. 


\section{El Festival Internacional de la Coca}

El segundo espacio importante de escenificación de la coca es el Festival Internacional de la Coca, que se organiza desde 2006 para celebrar el aniversario del distrito el día 9 de agosto. El festival dura cuatro días e incluye diversas actividades como la feria agropecuaria, agroindustrial y artesanal, carreras de autos, concursos de baile y belleza, conciertos y otras actividades culturales. En 2016 el concierto de cierre estuvo a cargo del grupo Los Kjarkas y todas las noches del festival se organizaron conciertos para la población, aunque fue el primer año en el que se cobró ingreso para dichos conciertos ${ }^{3}$.

$\mathrm{Al}$ ser días de fiesta, la mayoría de las actividades se paralizan en la ciudad, aunque las instituciones públicas del Gobierno central continúan funcionando normalmente, a diferencia de la Municipalidad. Es la ocasión en la que vienen productores y visitantes de todos los rincones del valle, e incluso llegan mototaxis provenientes de Ayacucho para responder a la gran demanda de transporte público durante los días del festival.

Es la festividad dedicada a la coca más importante del país, y convoca tanto a productores de coca del VRAEM como de las distintas cuencas cocaleras. Es también la ocasión para las reuniones de la Federación Nacional de Productores de Hoja de Coca. La visibilidad de la hoja de coca es permanente a lo largo del festival, por lo que nos detendremos a observar la escenificación de la misma en este espacio.

El escenario del festival, el campo ferial del distrito, muestra en su infraestructura imágenes de hojas de coca a cada lado de la inscripción "campo ferial», como se observa en la fotografía 4. A pesar de ser un recinto multiusos que sirve para diversos eventos durante todo el año, la imagen de la hoja de coca está constantemente presente en la infraestructura.

Toda la retórica del festival, incluyendo los nombres de sus actividades y sus afiches, se centra en torno a la hoja. Así, durante el festival se elige a la Miss Coca y se escenifica el Coca Raymi. Esta escenificación es uno de los actos centrales del festival, en el que se recrea las escenas del tradicional festival del Inti Raymi que se celebra en Cusco cada 24 de junio. En este sentido, esta escenificación trata de vincular el Festival de la Coca con tradiciones prehispánicas que aluden al carácter ancestral del mismo (Betanzos, 1996; Cobo, 1956). Sin embargo, a diferencia de la versión que se escenifica en Cusco, la coca está presente en cada sección del acto: las ofrendas que trae cada uno de los visitantes de los suyos son hojas de coca o arbustos de coca, como se observa en la fotografía 5.

3 El detalle de las actividades del festival puede revisarse en la web de la Municipalidad Distrital de Pichari (2016). 
Fotografía 4. Entrada principal del campo ferial de Pichari, local del Festival Internacional de la Coca

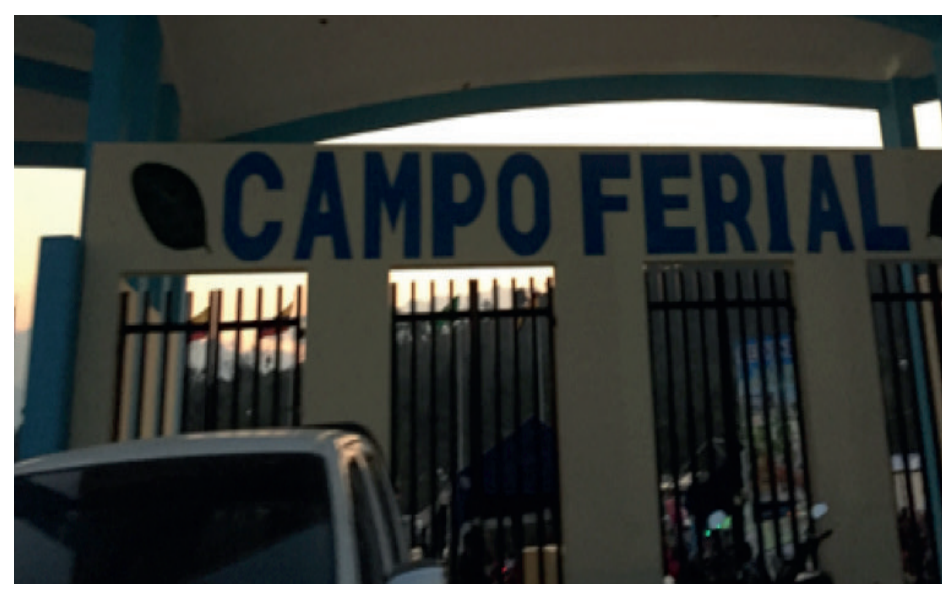

Fuente: Archivo fotográfico propio.

Fotografía 5. Participantes de la escenificación del Coca Raymi ofrenda de coca por parte de los suyos

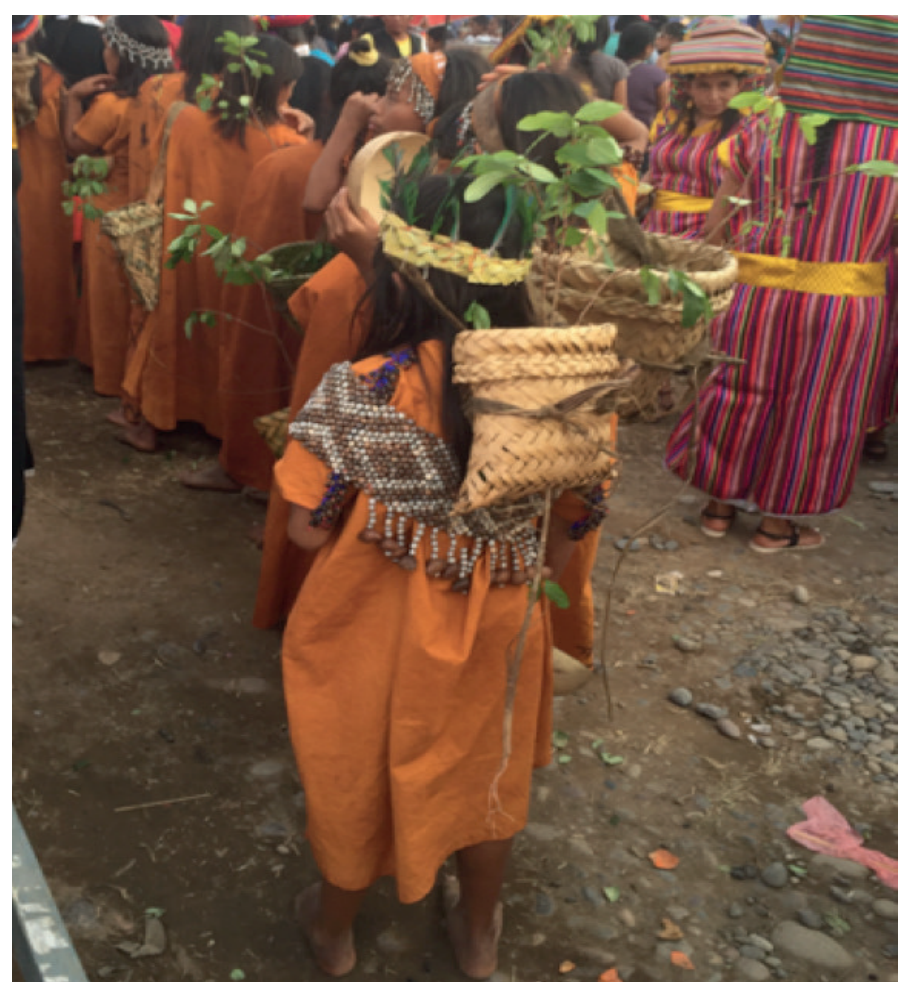

Fuente: Archivo fotográfico propio. 
Fotografía 6. Escenario central del Coca Raymi

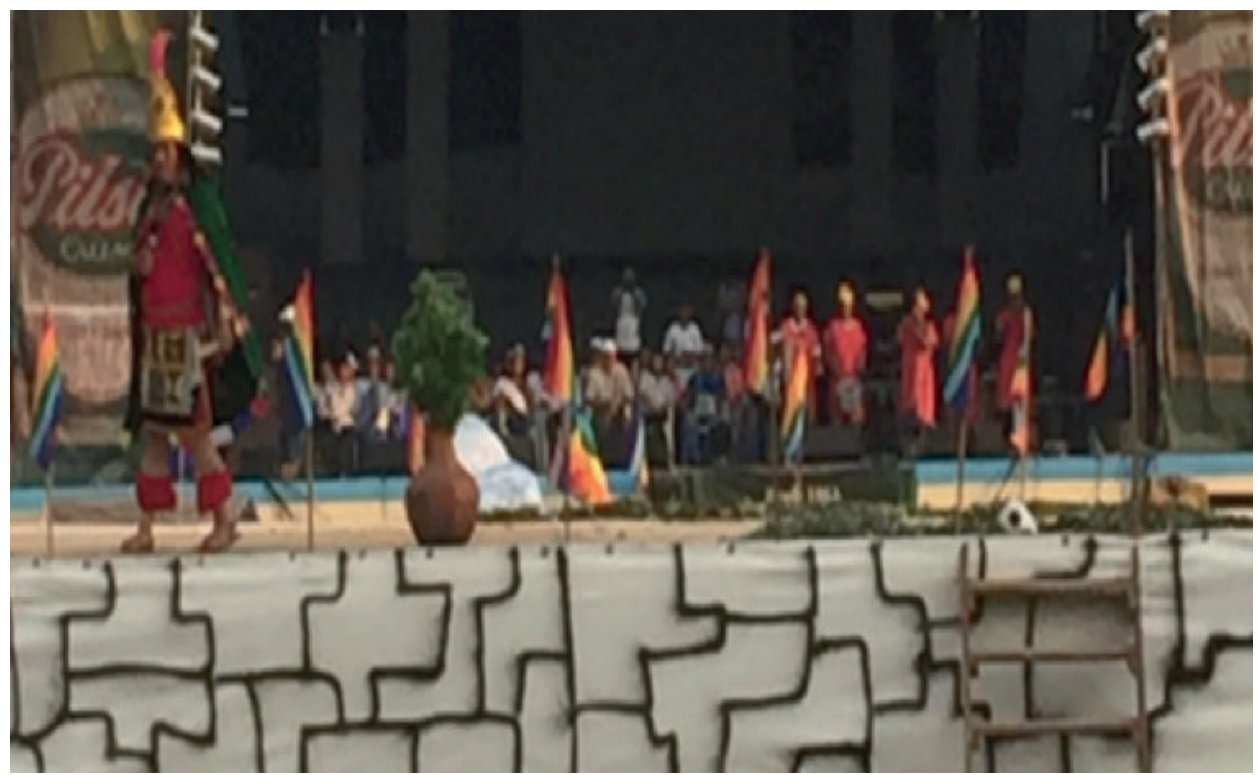

Fuente: Archivo fotográfico propio.

Asimismo, el Inca y la Colla participan de un ritual junto a un sacerdote en el que se rinde homenaje a la tierra y a la hoja de coca. En el centro del escenario se encuentran las hojas de coca en una especie de manta, como se observa en la fotografía 6.

Es decir, esta es una escenificación en la que el rol sagrado y ritual de la coca se expone en el primer plano. Esta escenificación dura casi tres horas y se realiza en el día central del festival. El público, entre los que se encuentran niños, personas de la tercera edad y visitantes, mira el festival desde los lados del campo en el que se celebra el Coca Raymi. Allí, la Municipalidad ha instalado toldos para proteger al público del sol. Los participantes de la escenificación son principalmente estudiantes de colegios e institutos del distrito, así como profesores, quienes han practicado durante varios meses para esta escenificación.

Además, la coca también está presente en los productos ofertados en el festival. La Municipalidad tuvo un stand en el que presentó bebidas rehidratantes y energéticas en base a la coca producidos por los proyectos que ha impulsado. Asimismo, hay una zona en la que productores del valle ofertan otros productos derivados de la coca como harina de coca, licor de coca, caramelos de coca y hasta coca sour. Asimismo, el símbolo de la ciudad, Coca Kinto, también se vende en los stands de artesanía de la feria. Los polos conmemorativos del festival que venden diversos comerciantes tienen frases como «la coca no es 
droga», que refuerza la vinculación con la hoja de coca legal. Así, el festival es la ocasión para revalorizar la imagen tradicional de la coca y poner en vitrina los usos industriales de la misma.

\section{Tensiones entre el Gobierno local y el Gobierno Central en TORNO A LA ESCENIFICACIÓN DE LA HOJA DE COCA}

La conexión entre el Gobierno local y el movimiento cocalero: el poder simbólico como favor político

Diversos trabajos ya han señalado la conexión entre autoridades locales y la defensa política de la hoja de coca (Durand, 2005; Zevallos y Mujica, 2013) e incluso la conexión entre autoridades locales y tráfico ilícito de drogas (López, 2014). Las tensiones entre Gobiernos locales y Gobierno nacional en el VRAEM en torno a la política de drogas también han sido exploradas desde la perspectiva de los discursos y las campañas electorales (López, 2014; Zevallos y López, 2010). Así, como lo afirma López (2014), la hoja de coca ha sido usada como recurso de estrategia en las campañas políticas locales, aunque la intensidad de su defensa ha variado en función de la coyuntura nacional. En Pichari, la relación entre autoridades locales y movimiento cocalero también ha existido, aunque ninguna de sus autoridades haya sido parte del movimiento político Qatun Tarpuy, como se aprecia en la tabla 4.

Tabla 4. Relación de los alcaldes de Pichari 1996-2017

\begin{tabular}{|c|c|c|}
\hline $\begin{array}{c}\text { Periodo de gestión } \\
\text { municipal }\end{array}$ & Nombre del alcalde & Agrupación política ganadora \\
\hline $\begin{array}{c}\text { 1996-1998 } \\
\text { (elecciones parciales })\end{array}$ & Carlos Edgar Pacheco Morales & L. I No 05 Desarrollo Integral de Pichari \\
\hline $1999-2002$ & Edilberto Floriano Gómez Palomino & Movimiento Independiente Vamos Vecinos \\
\hline $2003-2006$ & Miky Joaquín Dipas Huamán & $\begin{array}{c}\text { Movimiento Democrático Juntos por el } \\
\text { Progreso }\end{array}$ \\
\hline $2007-2010$ & Miky Joaquín Dipas Huamán & Unión por el Perú \\
\hline $2011-2014$ & Edilberto Floriano Gómez Palomino & Perú Posible \\
\hline $2014-20108$ & Amador Quinteros Villar & Somos Perú \\
\hline
\end{tabular}

Fuente: elaboración propia sobre la base de información disponible en Infogob.pe 
Existen indicios de que el movimiento cocalero ha apoyado a algunos candidatos a las elecciones locales. La revista Caretas en su nota «La plaza de la coca» señaló que el alcalde Dipas había llegado a su primera gestión municipal con el apoyo de Nelson Palomino y el movimiento cocalero (Chávez, 2008). Este apoyo explicaría la razón por la cual Qatun Tarpuy no presentó candidato a Pichari en las elecciones de 2006, a pesar de su fortaleza política en el resto del valle (Zevallos y López, 2010). Durante el trabajo de campo, varios de los entrevistados señalaron también que este apoyo político explicaba que fuese durante la gestión de Dipas que se construyese la plaza de Pichari con el Paseo de hojas de coca y se crease el Festival Internacional de la Coca. Aunque no se admita formalmente, la escenificación de la coca en la ciudad forma parte de los recursos simbólicos con los que cuenta el movimiento cocalero y las propias autoridades locales para expresar su desacuerdo con la política de drogas que busca erradicar la coca en el VRAEM. El mensaje que se construye a partir de este recurso es que atacar la coca es atacar parte de la identidad del distrito y no solamente a los cocaleros. El uso de este recurso permite promover la imagen de la coca no solo en el ámbito rural sino en el ámbito urbano y crear una identidad distrital asociada a ella, en la que tanto productores como no productores pueden reconocerse.

A pesar de que han existido pedidos por cambiar el nombre del festival a opciones como Festivraem (que luego fue adoptado para las festividades que se celebran en el distrito de Kimbiri), no se han realizado cambios que cuestionen a la imagen de la coca como parte de la «marca ciudad». Incluso en aquellos momentos de mayor debilidad política del movimiento cocalero, la escenificación de la coca ha continuado en la ciudad. Así por ejemplo, a pesar de que se han realizado al menos dos remodelaciones a la plaza de Pichari desde su construcción en 2005, ninguna ha eliminado el Paseo de hojas de coca, sino que se han aumentado mayores elementos. Si bien no es el único Gobierno local del VRAEM que emplea este recurso ornamental, es aquel que lo ha generalizado en las decoraciones de sus diferentes espacios públicos y ha logrado construir una imagen distrital asociada a la hoja de coca. Frente a ello, los representantes del Gobierno central han tenido reacciones que muestran su desacuerdo con esta escenificación.

\section{Las resistencias cotidianas a la escenificación de la coca desde los representantes del Gobierno central}

En Pichari es imposible vivir y trabajar en la ciudad sin toparse con la imagen de la hoja de coca en alguna de sus calles o plazas. La plaza central del distrito es el centro administrativo de la ciudad, congregando tanto instituciones 
del Gobierno local como del Gobierno central. En la plaza estuvieron ubicadas, hasta mediados del año 2016, las oficinas del Codevraem, de Osiptel, de Indecopi, de la OEFA, del Midis y del Ministerio Público, por lo que todos los días funcionarios de estas instituciones debían transitar por la plaza.

La escenificación de la hoja de coca en el espacio público es un constante recordatorio para los funcionarios del Gobierno central de que el problema al que muchos de ellos se les ha encargado combatir (el tráfico ilícito de drogas) no está solo confinado a espacios rurales y alejados, sino que permea su cotidiano. Uno de los funcionarios entrevistados incluso mencionó que en Pichari «es imposible no ser cómplice del narcotráfico, ya sea voluntaria o involuntariamente aquí todo tiene que ver con la coca».

$\mathrm{Si}$ bien es imposible evitar los espacios públicos, las instituciones del Gobierno central han evitado usar cualquier iconografía que haga referencia a la hoja de coca. Además evitan participar de las actividades durante el Festival Internacional de la Coca, al menos durante los días laborables. Así, durante los días del festival las oficinas del Gobierno central siguen atendiendo con normalidad en horario de oficina. Durante el año 2016, incluso se había programado talleres de capacitación sobre derechos laborales junto con el Gobierno Regional de Cusco y el Ministerio de Trabajo. A pesar de ser una actividad que buscaba congregar a más trabajadores locales, estos talleres solo contaron con la participación de los alumnos de los institutos locales a quienes sus profesores habían obligado a ir.

Los funcionarios locales señalaban que prefieren mantenerse al margen de las celebraciones a fin de evitar problemas, tanto por el hecho de que el festival exalta la hoja de coca, como por las acusaciones de corrupción que también circulan entre la población local en torno al festival. Algunos de los funcionarios acuden puntualmente a la feria de productores o a alguno de los conciertos, como parte de sus actividades recreativas de fin de semana, pero no lo realizan de manera institucional. Este año, la presencia del Gobierno central en la feria estuvo concentrada principalmente en el stand de la Policía Nacional del Perú y la Comisaría de Mujeres, quienes informaban a la comunidad sobre temas relacionados a la violencia de género. Algunos de los funcionarios en el stand mencionaban que el festival era una oportunidad que no podían desperdiciar, dada la cantidad de personas que congregaba. Durante mucho tiempo las fuerzas del orden evitaron participar del festival. Sin embargo, como parte del componente de acción cívica, han buscado formas de acercarse a la población, por ejemplo formando parte del jurado del concurso de bandas de establecimientos escolares que se realiza en el marco del festival. También 
varias de las oficinas participan del desfile del día central, que corresponde al aniversario de Pichari. Ello con el fin de no generar mayores problemas con el Gobierno local.

Sin embargo, el festival genera un clima de tensión entre los funcionarios de las instituciones del Gobierno central. Algunos sugieren que se le debería cambiar el nombre, a fin de convertirlo en un evento que atraiga turismo fuera del VRAEM. Otros se limitan a no participar de las celebraciones y se quejan de que durante esos días la ciudad está más llena y desordenada. Sin embargo, ni a nivel del espacio público ni en las festividades, las instituciones del Gobierno central han realizado una resistencia efectiva a la construcción de la identidad distrital en torno a la hoja de coca. Las resistencias aquí descritas son más del orden individual y personal que de orden colectivo e institucional. Así, en lo referente al contexto físico y simbólico de negociación de la política de drogas, es el Gobierno local el que ha llegado a asentar una presencia legítima de la hoja de coca entre los habitantes de la ciudad.

\section{Conclusiones}

La escenificación de la hoja de coca en el espacio y las festividades públicas ha servido como recurso de poder simbólico (Hallet, 2003) para definir el contexto de negociación de la implementación de la política de drogas en el distrito de Pichari. A partir de esta escenificación y de la movilización de narrativas tradicionales sobre la hoja, el Gobierno local ha encontrado un mecanismo de apoyo legítimo y legal a la defensa del cultivo. Esta legitimidad sirve de base para la construcción de una marca ciudad (Borja y Castells, 2000) cocalera. La coca forma parte de la identidad del distrito, por lo que permite la identificación de productores y no productores cocaleros.

Esto forma parte de los recursos que tiene el Gobierno local para la construcción de redes de soporte que apoyen su oposición a una política de drogas basada en la erradicación. Si bien las posiciones del Gobierno local se han moderado en torno a los componentes, como el desarrollo alternativo (López, 2014; Zevallos y López, 2010), aún subsisten tensiones en torno a la erradicación. Así, el movimiento cocalero aún moviliza a la población en el marco de la nueva ronda de negociaciones que se desarrolla con el Gobierno central desde mediados de 2016. En ese contexto, un nuevo paro cocalero fue convocado el primero de julio de 2017, en el que el movimiento volvió a manifestar públicamente su oposición a la erradicación. 
Asimismo, la escenificación sirve como un recordatorio permanente para que los funcionarios del Gobierno central acepten la presencia de la hoja de coca en el VRAEM. La relación entre Gobierno central y Gobierno local está marcada por diferentes tensiones en torno a la escenificación de la hoja de coca. A nivel micro, la escenificación causa incomodidad cotidiana y críticas de los funcionarios del Gobierno central, quienes intentan escapar de esta presencia. Sin embargo, a nivel macro no se han formulado críticas institucionales con respecto al uso de la imagen de la coca como marca ciudad. El margen de crítica de los funcionarios del Gobierno central es reducido, dado que no es legítimo criticar el carácter tradicional, e incluso la simbología política, que moviliza la imagen de la hoja de coca. En ese sentido, el caso de Pichari es un caso exitoso de movilización de recursos públicos de manera legal para la defensa política del cultivo de coca. Sin embargo, esta defensa no necesariamente puede evitar la implementación de la política de drogas, pero sí logra que a través de la identificación de la población con la hoja de coca se aumenten los costos sociales de una intervención basada en la erradicación.

\section{REFERENCIAS}

Acuto, F. A. (2012). Landscapes of Inequality, Spectacle and Control: Inka Social Order in Provincial Contexts. Revista Chilena de Antropologia, (25), 9-64. https://doi.org/10.5354/07191472.2012.20256

Agudo-Sanchíz, A. y Estrada, M. (eds.) (2011). (Trans)formaciones del Estado en los márgenes de Latinoamérica. México: UIA, El Colegio de México.

Bedoya, E. (2016). La deforestación y la tragedia de los comunes entre los cocaleros del VRAE: 2001-2004. Espacio y Desarrollo, (28), 75-101.

Bell, J. (1999). Redefining national identity in Uzbekistan: symbolic tensions in Tashkent's official public landscape. Ecumene, 6(2), 183-213.

Betanzos, J. (1996) [1557]. Narrative of the Incas. R. Hamilton y D. Buchanan, trads. y eds. Austin: University of Texas Press.

Borja, J. y Castells, M. (2000). Local y global: La gestión de las ciudades en la era de la información. Madrid: Taurus.

Bouysse-Casagne, T. (2005). Las minas del centro-sur andino, los cultos prehispánicos. Bulletin de l'Institut Français d'Études Andines, 34(3), 443-462.

Briscoe, I., Perdomo, C. y Uribe-Burcher, C. (2014). Redes Ilícitas y Política en América Latina. Estocolmo: IDEA Internacional, NIMD y el Instituto Clingendael.

Burchard, R (1974). La coca y el truque de alimentos. En G. Alberti y E. Mayer (eds.), Reciprocidad e intercambio en los Andes (pp. 209-251). Lima: Instituto de Estudios Peruanos.

Burchard, R. (1978). Una nueva perspectiva sobre la masticación de hoja de coca. América Indígena, 38(4), 809-835.

Cobo, B. (1956) [1653]. Historia del nuevo mundo. Biblioteca de Autores Españoles. Madrid: Atlas.

Daniels, S. (1993). Fields of vision: landscape imagery and national identity in England and the United States. Princeton, NJ: Princeton University Press. 
Durand, A. (2005). El movimiento cocalero y su (in)existencia en el Perú. Itinerario de Desencuentros en el río Apurímac. Bulletin de l'Institut Français d'Études Andines, 34(1), 103-126. https://doi. org/10.4000/bifea.5651

Garay, L. y Salcedo-Albarán, E. (2013) Narcotráfico, corrupción y Estados. Cómo las redes ilícitas han reconfigurado las instituciones en Colombia, Guatemala y Mexico. México: Debate.

Geertz, C. (1973). La interpretación de las culturas. Barcelona: Gedisa.

Goffman, E. (1967). Interaction Ritual: Essays in Face to Face Behavior. New Brunswick: Aldine Transactions.

Hallett, T. (2003). Symbolic power and organizational culture. Sociological Theory, 21(2), 128-149. https://doi.org/10.1111/1467-9558.00181

Instituto Indigenista Americano (1986). La coca andina: visión indígena de una planta satanizada. México D.F: Joan Boldó i Climent, editores.

Johnson, N. (1995). Cast in stone: monuments, geography, and nationalism. Environment and Planning: Society and Space, 13(1), 51-65 13. https://doi.org/10.1068/d130051

López, N. D. V. (2014). Los discursos políticos de las autoridades municipales sobre la hoja de coca en los distritos de Kimbiri y Pichari 2006-2010. Revista de Ciencia Política y Gobierno, 1(1), 157-178.

Mack, L. (2002). Ejes de tensión y agregación de la acción colectiva en el nivel municipal guatemalteco. En B. Levy y F. Lorenc (eds.), Crisis y conflicto en el capitalismo latinoamericano (pp. 249-272). Buenos Aires: Clacso.

Magnani, J. (2012). Da periferia ao centro: trajetórias de pesquisa em Antropologia Urbana. Coleção Antropologia Hoje. São Paulo: Ed. Terceiro Nome.

Marcus, G (1995). Ethnography in/of the World System: The Emergence of Multi-Sited Ethnography. Annual Review of Anthropology, 24, 95-117. https://doi.org/10.1146/annurev. an.24.100195.000523

Mattos, D. (2014). Coca y representación: La hoja de coca en la constitución de la nación boliviana en la época neoliberal. Latin American Research Review, 49(1), 23-38.

Mayer, E. (1993) Factores sociales en la revalorización de la coca. Debate Agrario, (17), 131-143. Lima: Centro Peruano de Investigaciones Sociales CEPES.

Mayer, E. (2004). Casa, chacra y dinero: Economias domésticas y ecología en los Andes. Lima: IEP.

Miranda, S. G. (2016). La hoja transfronteriza. El consumo de coca en las faenas mineras salitreras en el Norte Grande de Chile (1900-1930). Historia Crítica, (59), 101-121. https://doi. org/10.7440/histcrit59.2016.06

Montes de Oca, L. (julio-diciembre de 2015). Entre activistas, funcionarios e industriales. Aplicación de la etnografía —enfocada y política - en escenarios de gobernanza. Nueva Antropología, 28(83), 25-46.

Municipalidad Distrital de Pichari (2016). Programa General de Actividades por el XII Festival Internacional de la Hoja de Coca 2016 (por partes). [Imágenes]. Municipalidad Distrital de Pichari. http://munipichari.gob.pe/programa-general-de-actividades-por-el-xii-festivalinternacional-de-lahoja-de-coca-2016-por-partes

Nash, D.J. (2012). El Establecimiento de relaciones de poder a través del uso del espacio residencial en la provincia wari de Moquegua. Bulletin de l'Institut d'Estudes Andines, 41(1), 1-34. https:// doi.org/10.4000/bifea.1003

Nash, D. J. y Williams, P. R. (2005). Architecture and power: Relations on the Wari-Tiwanaku frontier. En K. Vaughn, C. Conlee y D. Ogburn (eds.), The foundations of power in the Prehispanic Andes (pp. 151-174). Archaeological Papers of the American Anthropological Association 14. https://doi.org/10.1525/ap3a.2005.14.151

Nickson, R. A. (1995). Local government in Latin America. Boulder, CO: Lynne Rienner Publishers. 
Orche, E. (2008). Coca y minería en el Alto Perú durante el período colonial. Revista Metallica, 10(11), 99-107.

Radcliffe-Brown, A. (1958). El Método de la Antropología Social. Barcelona: Anagrama.

Rospigliosi, F., Blondet, C. y Lloréns, J. A. (2004). El consumo tradicional de la hoja de coca en el Perú. Lima: Instituto de Estudios Peruanos.

Strauss, A. (1978) Negotiations: Varieties, Contexts, Processes, and Social Order. San Francisco, CA: Jossey-Bass.

Tellería, L. (2013). Bolivia y la despenalización de la hoja de coca como estrategia de cambio. URVIO, (13), 95-107.

Weiss, R. (1995). Learning from stranger: the art and method of qualitative interview studies. Nueva York: Simon and Schuster.

Zevallos, N. y López N. (2010). Tensiones en la gestión de los gobiernos locales en zonas cocaleras. Politai. Revista de Ciencia Politica, 1(1), 74-84.

Zevallos, N. y Mujica, J. (2013). Consideraciones sobre las tensiones en la intermediación política en el movimiento cocalero en el Perú. Debates en Sociología, (38), 5-28.

Ziccardi, A. (coord.) (1991). Ciudades y gobiernos locales en América Latina de los noventa. México: Porrúa.

\section{Fuentes estadísticas}

INEI (2012) IV Censo Nacional Agropecuario. Lima: Instituto Nacional de Estadística e Informática. Disponible en http://proyectos.inei.gob.pe/CenagroWeb/

INEI (2004). Encuesta Nacional de Hogares sobre consumo tradicional de hoja de coca, 2003. Lima: Instituto Nacional de Estadística e Informática.

INEI-Devida (2015). Análisis de los Resultados de la Encuesta de Hogares sobre Demanda de la Hoja de Coca 2013. Lima: Instituto Nacional de Estadística e Informática.

MEF-Ministerio de Economía y Finanzas (2005). OPI Municipalidad Distrital de Pichari. Ficha de registro-Banco de Proyectos. http://ofi2.mef.gob.pe/bp/ConsultarPIP/frmConsultarPIP.asp?acc ion $=$ consultar $\&$ txtCodigo $=23858$

MEF-Ministerio de Economía y Finanzas (s/f) Consulta amigable. Consulta de Ejecución del Gasto de la Municipalidad de Pichari. http://apps5.mineco.gob.pe/transparencia/mensual/

UNODC (2016). Perú: Monitoreo de Cultivos de Coca 2015. Lima: Oficina de las Naciones Unidas contra las drogas y el delitos - UNODC y Comisión Nacional para un Vida sin Drogas - Devida.

\section{Fuentes legales}

Tribunal Constitucional (2008). Sentencia del pleno jurisdiccional del Tribunal Constitucional. Proceso de inconstitucionalidad. Pleno jurisdiccional 006-2008-PI/TC. http://www.tc.gob.pe/ jurisprudencia/2008/00006-2008-AI.html

\section{Fuentes periodísticas}

Chávez, E. (19 de junio de 2008). La coca tiene su propia plaza. Revista Caretas, pp. 48-50.

La República (28 de setiembre de 2005). TC anula ordenanzas regionales que legalizaron cultivos de coca. La República. http://larepublica.pe/28-09-2005/tc-anula-ordenanzas-regionales-quelegalizaron-cultivos-de-coca. Última fecha de consulta: 21 de julio de 2017. 